\title{
The strategic management of backyard poultry farming: The scenario in rural India
}

\author{
S. Banerjee ${ }^{1}$ and B. Ghosh ${ }^{1 *}$ \\ ${ }^{1}$ Neucrad Agri Farm Health LLP, Machalandapur, Kalna, East Burdwan, West Bengal, India
}

\begin{abstract}
The socio-economic and nutritional benefits of small-scale backyard poultry farming were well-known throughout the globe. In India, rural people also initiated to adopt this model for the improvement of their well-being. The backyard poultry farming concept is becoming more popular among resource-poor farmers in rural areas. This practice provides a high economic return with alow initial investment. This small-scale poultry sector not only economically supports the rural families but also, gets the source of nutritious foods as poultry meat and eggs. Apart from these, such a small-scale local business model is ideal for the economic independence and empowerment of rural women. Still, several hurdles and limitations need to be overcome for the successful establishment of backyard poultry farming in rural India as the high mortality rate in chicks, lack of proper infrastructure, the unstable production rate of desi breeds, lack of scientific knowledge for handling the birds, predators, harsh climatic exposures and most importantly, the fluctuations of the price of feed and feed supplement. In this review, we comprehensively discuss these constraints, benefits of the cooperative small-scale poultry farming model with the support of microfinancing institutions, scientific skill developments, and strategic management for the overall improvement of backyard poultry farming.
\end{abstract}

Key words: Backyard poultry farming, Breed, Food production, Health management, Poultry feed

\section{Highlights}

- The review is helpful to understand the basic management of backyard poultry farming.

- In this review, we discuss different aspects and benefits of the microfinance cooperative poultry model.

- The review is quite important to add value for improving the food security and sustainable development of poultry farming.

- We discuss the importance of micro-entrepreneurship training on poultry farming in rural areas.

- The review emphasizes the role of rural women empowerment in small-scale poultry farming.

\section{Introduction}

Food is an essential and indispensable part of our life. The worldwide sources of food are agriculture and livestock. These two important farming practices have immense contributions to the world as well as the Indian economy (Gowane et al., 2019). The development and maintenance of livestock are considered an integral part of the Indian agriculture system and contribute in many ways to the growth and development of the small agricultural sector especially in rural areas (Banda et al., 2021). Livestock provides financial assistance in the production of nutritious food products, in generating income and employment, and timely support during droughts. In addition, livestock farming is an essential and promising practice for environmental protection, ecosystem integrity, bio-energy supply, production of biofertilizers, bio-fuels that save on the use of nonrenewable energy sources and greatly reduce environmental pollution (Scherr et al., 2008). Therefore, apart from agriculture, the growing population in emerging and developing countries like India gets its food requirements from livestock. Among different animal

*Corresponding Author, E Mail: ghosh.biswarup@gmail.com 
agriculture practices, poultry farming provides a good, sustainable source of meat and eggs as a daily requirement across the country (Vaarst et al., 2015).

In the current scenario, poultry farming has been growing at a very fast rate and is still expected to show a climb high in the future. According to the $20^{\text {th }}$ Livestock Census report, it was estimated that total poultry birds in India count as 851.8 million. Interestingly, among them, 250 million (near about 30\%) are considered as 'backyard poultry' mainly maintained by small and marginal farmers (Padhi et al., 2016). The small farmers (who have $5,000-25,000$ poultry birds) in the rural areas of Andhra Pradesh, Karnataka, Tamil Nadu, Telangana, Maharashtra, West Bengal, Kerala and Assam have the highest poultry populations (Kolluri et al., 2019). Indian small farmers generally reared chickens, turkeys, ducks and geese for poultry purposes. Worth mentioning that, India has made considerable development in the production of broiler chicken during the last two decades. With the rise of scientific and technological advancements, poultry farmers are introducing high-quality breeds, standard poultry farming equipment, good rearing infrastructure, vaccines, and effective medicines to maintain healthy poultry chickens. As a result, India achieved the ranks of the fifth largest producer of poultry broiler and the fourth-largest producer of eggs in the world as well (Hafez et al., 2020).

\section{Importance of backyard poultry farming in India}

Although poultry farming has shown a very promising and rising trend in recent days, the major growth of this industry was found confined in urban or semi-urban areas of the country. It is easily understandable that most of the rural population don't have opportunities to access fresh eggs and chicken meat from intensive farming or commercial poultry sectors due to a lack of proper preservation facilities and very little demand for processed meat (Devi et al., 2014). It's a fact that $65 \%$ of the Indian population is estimated as rural people (Kumar et al., 2020) and their staple food is carbohydrates like rice and wheat. They don't get a substantial amount of protein from their daily food. Therefore, it is extremely important to protect them from malnutrition and associated diseases by providing them with balanced nutrition with animal protein supplements. To overcome this issue, along with the intensive poultry production system, backyard poultry farming (BYPF) using highquality chicken breeds or native breeds is not only drawing huge attention but also acquiring popularity in the rural population to resolve the problems of hunger, malnutrition and protein deficiency (Alders et al., 2018). Moreover, BYPF would be a potential subsidiary income source among the rural people in our country (Kumar et al., 2021).

\section{Phases of backyard poultry farming}

There are two important phases of backyard poultry farming including, a) nursery rearing and $b)$ free-range rearing.

a) Nursery rearing: The most important point in nursery rearing is artificially providing proper feed, temperature, protection to the newborn chicks (Hedlund et al., 2019). This phase is extremely important in backyard farming as it resembles intensive poultry farming in the context of quality feeding, proper management, and good health care practices (Rajkumar et al., 2021). In this phase, chicks are reared until they reach the age of 4-6 weeks and mature enough to start scavenging their feed and protect themselves from their surrounding predators.

b) Free-range rearing: Another important phase in which chicks ( between 4-6 weeks of age) are familiarized into the backyards carefully. Poultry farmers should observe the seasonal temperature before introducing the chicks in the backyard. The total number of domestic chicks mainly depends on the availability of area coverage and the source of natural feed. According to experts, a total of $15-20$ chicks per family is an ideal number for effective free-range rearing.

It was observed that up to 200 chicks are 
ideal for rearing under a small-scale freerange phase. In that case, chicks are needed a large foraging area and a hygienic poultry house for their night shelter (Tufarelli et al., 2018).

To get optimum productivity from chicken, 'supplementary feeding' is of utmost importance. In general, chickens reach their protein requirements during foraging in backyards. They scavenge on insects, soil worms, etc. After foraging in the daytime, the chickens should be fed with cereal grains and oilseed cakes in the evening. Through this process, chickens are meet the basic requirements of essential nutrients (Tufarelli et al., 2018). Farmers should give the mixture of stone grit, shell grit, or lime powder as a calcium supplement during the egg-laying phase (Wakenell et al., 2016). It was proven that without proper calcium supplements, chickens often lay brittle or broken eggs, even shell-less eggs (An et al., 2016).

\section{The usefulness of small-scale intensive poultry farming in the rural area}

Small-scale intensive poultry farming is mostly practiced by rural, resource-poor people who often experience food insecurity throughout the year. Such a poultry farming model is easily accessible to those rural people, and most importantly it could be a good income and nutritious food source for them to improve food security (Kumaresan et al., 2008). Not only does small-scale poultry farming enhance nutrient utilization in a better way, but also it greatly contributes to mixed farming practices and women empowerment in rural India (Nordhagen et al., 2018). Generally, poultry farmers should start small-scale intensive farming including 200 to a few thousand chickens, which could be reared in a similar way to intensive broiler farming. Intensive farming should be continued till chickens reach a bodyweight of about $1.5 \mathrm{~kg}$ in a flock. Such practice is beneficial for the production of meat by using fast-growing chicken varieties including, Krishibro, Vanaraja, Kuroiler, Srinidhi and Rainbow Rooster (Rajkumar et al.,
2021). It was estimated that about $10-20 \%$ of the backyard poultry farming is continued with this model system, especially in north-eastern states, and large areas in Himachal Pradesh (Thakur et al., 2012). Apart from the beneficial side of extensive small-scale poultry production systems, rural farmers often face significant obstacles to getting full benefits due to disease and predation. Such problems can be overcome with better agricultural and livestock management (Conan et al, 2012).

\section{The management of small-scale intensive poultry farming}

Studies demonstrated that native village chickens are useful and an important income source for domestic expenses. Traditional freerange poultry production systems in developing countries can be improved with the proper use of quality dual-purpose chickens (Kumaresan et al., 2008). Important Indian chicken breeds which were documented for small scale intensive poultry farming including, Ankleshwar, Aseel, Daothigir, Busra Chittagong, Denki, Haringhatta black, Ghagus, Kadaknath, Kashmir Faverolla, Kalasthi, Miri, Tellichery, Punjab Brown, Titri, Nicobari, Teni, frizzle fowl and Naked neck (Agarwal et al., 2020). Apart from the documented breeds, some desi chicken breeds are also reported (Sankhyan et al., 2013). According to research, scientists have found eight different strains of native chickens which are identified and reared by the rural peoples of East Godavari district of Andhra Pradesh including, Shankarjati Kodi, Nati Kodi, Medajari Kodi, Geesa Kodi, Rencha Kodi, Mattedu Kodi, etc. Interestingly, these indigenous breeds are Aseel in origin which has great value for their tasty meat, good fighting abilities, agility, and quick escape ability from their predators (Padhi et al., 2016). But farmers need to keep in mind that native chickens are slow growers in nature. Naturally, desi hens lay about 50-100 eggs in a year with alternating brooding phases. As discussed earlier, Aseel meat is superior in quality and composition; therefore, it is very popular among native 
chickens compared to commercial broilers (Rajkumar et al., 2016). It was observed that the native chickens are slow-growers and also poor layers in nature but they have the qualities to be ideal as a brooder, exceptional foragers, robust-bodied, and resistant to seasonal diseases (Rajkumar et al., 2017).

Maintaining good chicken varieties which are highly productive, have better immunity against seasonal diseases with a short budget for nutrition and management is challenging for the farmer. Therefore, farmers always need to maintain good breeds or varieties. The researcher suggested good ways to introduces elective breeding in already established desi breeds and also crossbreeding with exotic varieties or native breeds (Rajkumar et al., 2021). Besides breeding, nutrition plays a crucial role in regulating the genetic potential of the poultry chickens for improving the numbers and quality of eggs, also maintaining their body weight. Well-adjusted nutrition should provide young chicks with their overall health improvements and proper functioning of body metabolism (Cherian et al., 2015). Of note, the requirements of nutrients vary with the type of breed, body size, genetic makeup, age, the temperature inside the poultry, physical stressors, etc. (Barzegar et al., 2020).

The importance of night shelter in backyard poultry was always mentioned by different experts (Conan et al., 2012). Therefore, night shelter infrastructure should be proper for the birds to protect them from predators and adverse outside environmental conditions. The types of night shelters are variable and largely depend on the flocks' size as well as available resources (Al-Qamashoui et al., 2014). In India, smallscale and intensive poultry farmers usually made night shelter constructions with asbestos roofs, concrete walls (made up of cement instead of mud), and wire mesh for cross-ventilation purposes (Zhao et al., 2014). It was estimated that a poultry bird ideally requires one square feet space for their growing phase and around 2.5 square feet during the egg-laying phase inside the night shelter (Kumar et al., 2013).

Another important aspect of the backyard poultry management system is always to keep an eye on the health issues of birds. The studies showed that health management in poultry largely depends on bio-security and proper vaccination (Hofacre et al., 2002). Maintaining the highest level of bio-security like the commercial sector could be difficult for backyard poultry farmers such as proper immunization of birds under the scavenging system, veterinary facilities, protection from predator attacks were considered main constraints for the small-scale poultry farmers (Hossain et al., 2021). The most predominant chicken diseases were found as Newcastle disease and Fowlpox. These viral diseases show remarkable infectivity in the hot and humid coastal regions, therefore periodic vaccination is extremely important to protect the flocks (Hassan et al., 2020). Also, the chickens are naturally exposed to different pathogenic loads while scavenging and need continuous monitoring of their health conditions. If some disease symptoms appear, immediately the diseased birds should be separated from others and need to take necessary measures (Galarneau et al., 2020). Despite the several limitations, it is recommended to practice mass vaccination programs with the help of local NGO teams, veterinary experts, Govt. departments to control the viral diseases effectively (Kumar et al., 2015). It was a proven fact that the proper use of a thermostable vaccine has successfully decreased the Newcastle disease infection in backyard poultry farming (Dey et al., 2017). Apart from this, there are possibilities for poultry birds for exposing different other pathogens including, avian influenza, infectious bronchitis, infectious bursal disease and Marek's disease which are potential causes of significant morbidity and mortality (Fulton et al., 2013). Some bacterial and parasitic diseases also cause harm to the poultry birds but can be prevented with proper vaccination and biosecurity measurements (Hauck et al., 2017). According to research, both bacterial and parasitic infections occur from the source of contaminated poultry feed and water. To prevent such situations, mass deworming 
should be done in specific time intervals (six months intervals recommended) (Bessell et al., 2019). It is generally suggested to apply deworming-related medications a week before the vaccination of poultry birds to prevent viral diseases. Several studies identified the potential source of contamination as sewerage in the backyards. The contaminated water mostly contains different harmful intestinal parasites including cestodes, nematodes and trematodes, which affect the health and hygiene of poultry birds (Asumang et al., 2019) and could be a reason for huge losses to the poor farmers. Other sources of external parasites are night shelter houses or poultry rooms with unhygienic conditions such as the damp, moist, wet floor, and poor ventilation systems (Singh et al., 2017). Therefore, experts always suggest to poultry farmers to keep breeding and rearing areas clean with proper disinfectants (Fig. 1). Small-scale intensive poultry farming needs proper surveillance, training, reporting as well as the documentation of breeding history, abnormal symptoms of birds, vaccination, mortality trends if concerned, etc. (Thornton et al., 2010)
Antibiotic resistance in poultry birds is a matter of concern now. Data suggested that substantial anti-microbial resistance of $E$. coli bacteria in chicken was developed in most of the poultry farms worldwide. Interestingly, Norway and Sweden had good practices for using fewer antibiotics showed lower levels of E. coli resistant in poultry birds (Wierup et al., 2021). According to research, overuse of antibiotics may have some adverse effects on chicken such as administration of tetracyclines for a long time may show metabolic deregulations and immunosuppressive effects. For these reasons, there was a reduction of normal intestinal microbiota observed in the gut of poultry birds and they become more prone to different opportunistic infections (Shang et al., 2018). During excessive antibiotic treatment, commensal microbes are destroyed in young birds and there is a fair chance to develop harmful bacteria and coccidia populations (Noack et al., 2019). Prolonged use of other two antibiotics including, aminoglycosides and sulfonamides may damage the kidney and weaken the minerals absorption capacity in poultry birds (Mund et al., 2017). Also, the overdose of steroid

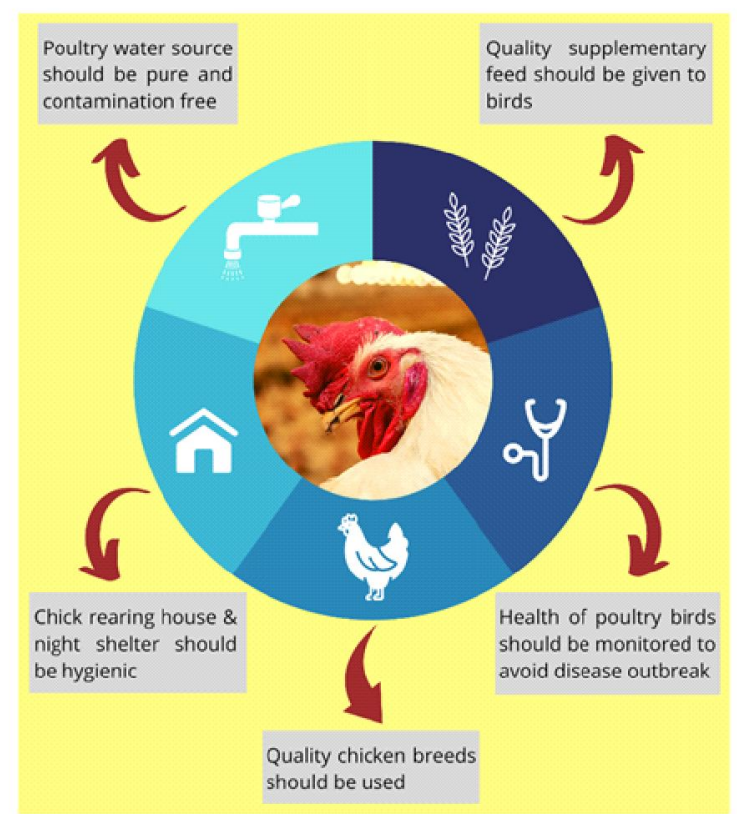

Fig. 1. Strategic components for small-scale intensive poultry management 
hormone therapy demonstrated a negative effect on chicken's health and sometimes causes food toxicity (Jeong et al., 2010).

\section{Importance of microfinancing co-operative poultry farming model in rural India}

The micro-financing cooperative poultry farming model was considered beneficial for small-scale intensive farmers who own the local poultry farms and together run and share the profits (Kumar et al., 2015; Chaiban et al., 2021). The successful cooperative poultry model was established by a nonprofit organization in the central part of India with nearly 10,000 farmers. Importantly, most of them were rural women, previously involved in other manual laborworks. After successful training on poultry management, women farmers were provided with initial monetary support by giving a part loan to build the poultry farming infrastructures. In this model system, each farmer is required to start work with 300-400 chicks. Currently, they work with 6001000 chickens/batch, and the estimated productivity level is 220 eggs/chicken/year. Moreover, the health and hygiene issues of each poultry farm (known as a cluster) are monitored by the team of para-veterinary personals (Beesabathuni et al., 2018). Nowadays, several microfinance organizations are supporting smallscale intensive poultry farmers in rural areas. The cooperative model was successful in India because of the flourishing and fast-growing input industries, giving procurement at affordable prices for different NGOs to help poor farmers. Studies also suggested that India achieved the position of the third-largest producer of eggs in the world, mostly with the collective efforts of medium and large-scale poultry farms (Chatterjee et al., 2015).

\section{Discussion}

Backyard poultry farming could be an excellent initiative for rural people of India and may play an important role in improving food security and sustainable development. In this current scenario, small-scale poultry farmers are facing hurdles at the initial stage of their business establishments but strategic management and support from NGOs, social volunteers, Govt. sectors are expected to increase the net productivity and costeffectiveness of backyard poultry farming (Fig. 2). Scientists already identified the major

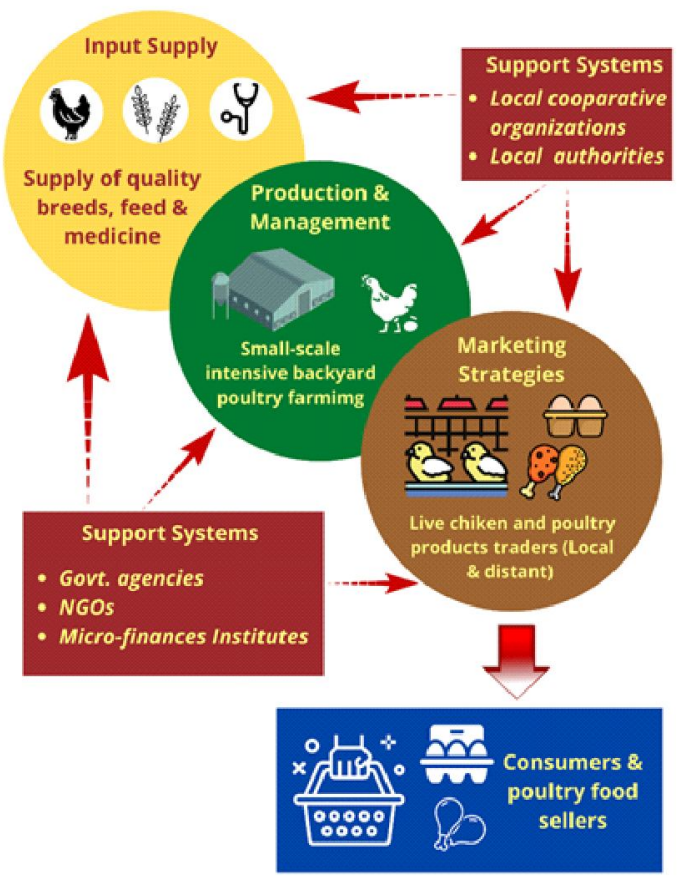

Fig. 2. Support systems and sequential chain of small-scale intensive poultry farming model 
hurdles in this field including, unavailability of superior breeds, poor health and hygiene, recurrent emergence of viral diseases in poultry birds, antibiotic resistance-related problems, inappropriate infrastructure for rearing house and night shelters, the high price of chicken feed supplements, a high mortality rate of the birds, etc. With the advancement of animal husbandry research, effective and low price vaccines, quality supplemental feeds, disinfectants, and improved poultry water sanitization systems are available now in the market. Therefore, it is anticipated that challenges and limitations will reduce to a substantial level soon. Also, the practice of backyard poultry farming will give the benefit of economic independence to the rural women who are actively involved in this small business. Farmers need to comprehend the importance of native and better-quality breeds for the improved production of eggs and meat as they have a good demand nowadays. Overall, the cooperative backyard poultry farming model

\section{REFERENCES}

Agarwal S, Prasad S, Kumar R and Chandra S, 2020. Molecular characterization of native chicken: prospects and challenges. J Entomol Zool Stud, 8(SP-2): 103-106

Alders RG, Dumas SE, Rukambile E, Magoke G, Maulaga W et al., 2018. Family poultry: multiple roles, systems, challenges, and options for sustainable contributions to household nutrition security through a planetary health lens. Matern Child Nutr, 14(S3): e12668, doi: 10.1111/ mcn. 12668

Al-Qamashoui B, Mahgoub O, Kadim I and Schlecht E, 2014. Towards conservation of omani local chicken: phenotypic characteristics, management practices and performance traits. Asian-Australas J Anim Sci, 27(6): 767-777, doi: 10.5713/ ajas.2013.13541

An SH, Kim DW and An BK, 2016. Effects of dietary calcium levels on productive performance, eggshell quality and overall calcium status in aged laying hens. Asian-Australas J Anim Sci, 29(10): 1477-1482, doi: 10.5713/ajas.15.0655

Asumang P, Akoto Delali J, Wiafe F, Kamil Z, Iddrisu will be beneficial and environment-friendly if proper strategic planning and training are provided to the poultry farmers on regular basis.

\section{Conclusion}

In order to achieve maximum benefits from backyard poultry farming, strategic and systemic training is required for rural communities. In addition, technical and motivational support should be provided to encourage farmers for running small-scale backyard poultry production systems, since this is an important sustainable agricultural practice for increasing food production, food security, and women empowerment and employment to the rural Indian population.

Conflict of interest: Authors have no conflict of interest in this study.

Author's contribution: SB, BG: Conceptualized the review and have made a direct, significant and intellectual contribution to this work.

Balali G et al., 2019. Prevalence of gastrointestinal parasites in local and exotic breeds of chickens in Pankrono-Kumasi, Ghana. J Parasitol Res: 5746515, doi: 10.1155/2019/5746515

Banda LJ and Tanganyika J, 2021. Livestock provide more than food in smallholder production systems of developing countries. Anim Front, 11(2): 7-14, doi: 10.1093/af/vfab001

Barzegar S, Wu SB, Choct M and Swick RA, 2020. Factors affecting energy metabolism and evaluating net energy of poultry feed. Poult Sci, 99(1): 487-498, doi: 10.3382/ps/pez554

Beesabathuni K, Lingala S and Kraemer K, 2018. Increasing egg availability through smallholder business models in East Africa and India. Matern Child Nutr, 14(S3): e12667, doi: 10.1111/ mcn. 12667

Bessell PR, Dash R, Prasad S, Al-Riyami L, Gammon N et al., 2019. Estimating the impact of administration of dewormers on smallholder chickens in Odisha State, India. Poult Sci, 98(4): 1692-1696, doi: 10.3382/ps/pey526

Chaiban C, Da Re D, Robinson TP, Gilbert M and 
Vanwambeke SO, 2021. Poultry farm distribution models developed along a gradient of intensification. Prev Vet Med, 186: 105206, doi: 10.1016/j.prevetmed.2020.105206

Chatterjee RN and Rajkumar U, 2015. An overview of poultry production in India. Indian J Anim Hlth, 54(2): $89-108$

Cherian G, 2015. Nutrition and metabolism in poultry: role of lipids in early diet. J Anim Sci Biotechnol, 6: 28, doi: 10.1186/s40104-015-0029-9

Conan A, Goutard FL, Sorn S and Sirenda V, 2012. Biosecurity measures for backyard poultry in developing countries: A systematic review. BMC Vet Res, 8: 240, doi: 10.1186/1746-6148-8-240

Devi SM, Balachandar V, Lee SI and Kim IH, 2014. An outline of meat consumption in the Indian population - A pilot review. Korean J Food Sci Anim Resour, 34(4): 507-515, doi: 10.5851/ kosfa.2014.34.4.507

Dey S, Chellappa MM, Pathak DC, Gaikwad S, Yadav $\mathrm{K}$ et al., 2017. Newcastle disease Virus vectored bivalent vaccine against virulent infectious Bursal disease and Newcastle disease of chickens. Vaccines, 5(4): 31, doi: 10.3390/ vaccines 5040031

Fulton JE, Arango J, Arthur JA, Settar P, Kreager KS et al., 2013. Improving the outcome of a Marek's disease challenge in multiple lines of egg type chickens. Avian Dis, 57(S2): 519-522, doi: 10.1637/10408-100212-Reg.1

Galarneau KD, Singer RS and Wills RW, 2020. A system dynamics model for disease management in poultry production. Poult Sci, 99(11): 55475559, doi: 10.1016/j.psj.2020.08.011

Gowane GR, Kumar A and Nimbkar C, 2019. Challenges and opportunities to livestock breeding programmes in India. J Anim Breed Genet, 136(5): 329-338, doi: 10.1111/jbg.12391

Hafez HM and Attia YA, 2020. Challenges to the poultry industry: current perspectives and strategic future after the COVID-19 outbreak. Front Vet Sci, 7: 516, doi: 10.3389/fvets.2020.00516

Hassan MSH and Abdul-Careem MF, 2020. Avian viruses that impact table egg production. Animal, 10(10): 1747, doi:10.3390/ani10101747

Hauck R, 2017. Interactions between parasites and the bacterial microbiota of chickens. Avian Dis, 61(4): 428-436, doi: 10.1637/11675-051917-Review.1

Hedlund L, Whittle R and Jensen P, 2019. Effects of commercial hatchery processing on short- and longterm stress responses in laying hens. Sci Rep, 9: 2367, doi: 10.1038/s41598-019-38817-y
Hofacre CL, 2020. The health and management of poultry production. Int J Infect Dis, 6(S3): S3-S7, doi: 10.1016/S1201-9712(02)90177-3

Hossain ME, Hoque MA, Giorgi E, Fournié G, Das GB et al., 2021. Impact of improved small-scale livestock farming on human nutrition. Sci Rep, 11: 191, doi: 10.1038/s41598-020-80387-x

Jeong SH, Kang D, Lim MW, Kang CS and Sung HJ, 2010. Risk assessment of growth hormones and antimicrobial residues in meat. Toxicol Res, 26(4): 301-313, doi: 10.5487/TR.2010.26.4.301

Kolluri G, Tyagi JS and Sasidhar PVK, 2021. Research note: Indian poultry industry vis-à-vis coronavirus disease 2019: A situation analysis report. Poult Sci, 100(3): 100828, doi: 10.1016/ j.psj.2020.11.011

Kumar A, Nayar RK and Koya SF, 2020. COVID-19: Challenges and its consequences for rural health care in India. Public Health Pract, 1: 100009, doi: 10.1016/j.puhip.2020.100009

Kumar M, Dahiya SP and Ratwan P, 2021. Backyard poultry farming in India: A tool for nutritional security and women empowerment. Biol Rhythm Research, 52(10): 1476-1491, doi: 10.1080/ 09291016.2019 .1628396

Kumar P, Churchil R, Jalaludeen A, Narayanankutty $\mathrm{K}$, Joseph L et al., 2013. A survey on village chicken production in Kerala state of India. World's Poult Sci J, 69(4): 917-930, doi: 10.1017/ S0043933913000925

Kumar V, Wankhede KG and Gena HC, 2015. Role of cooperatives in improving livelihood of farmers on sustainable basis. Am J Edu Res, 3(10): 12581266, doi: 10.12691/education-3-10-8

Kumaresan A, Bujarbaruah KM, Pathak KA, Chhetri B, Ahmed SK et al., 2008. Analysis of a village chicken production system and performance of improved dual purpose chickens under a subtropical hill agro-ecosystem in India. Trop Anim Health Prod, 40(6): 395-402, doi: 10.1007/ s11250-007-9097-y

Mund MD, Khan UH, Tahir U, Mustafa BE and Fayyaz A, 2017. Antimicrobial drug residues in poultry products and implications on public health: A review. Int J Food Prop, 20(7): 1433-1446, doi: 10.1080/10942912.2016.1212874

Noack S, Chapman HD and Selzer PM, 2019. Anticoccidial drugs of the livestock industry. Parasitol Res., 118(7): 2009-2026, doi: 10.1007/ s00436-019-06343-5

Nordhagen S and Klemm R, 2018. Implementing smallscale poultry-for-nutrition projects: successes and 
lessons learned. Matern Child Nutr, 14(S3): e12676, doi: $10.1111 / \mathrm{mcn} .12676$

Padhi MK, 2016. Importance of indigenous breeds of chicken for rural economy and their improvements for higher production performance. Scientifica: 2604685, doi: 10.1155/2016/2604685

Rajkumar U, Haunshi S, Paswan C, Raju MVLN, Rama Rao SV et al., 2017. Characterization of indigenous Aseel chicken breed for morphological, growth, production and meat composition traits from India. Poult Sci, 96(7): 2120-2126, doi: $10.3382 / \mathrm{ps} / \mathrm{pew} 492$

Rajkumar U, Muthukumar M, Haunshi S, Niranjan M, Raju MVLN et al., 2016. Comparative evaluation of carcass traits and meat quality in native Aseel chickens and commercial broilers. British Poult Sci, 57(3): 339-347, doi: 10.1080/ 00071668.2016 .1162282

Rajkumar U, Rama Rao SV, Raju MVLN and Chatterjee RN, 2021. Backyard poultry farming for sustained production and enhanced nutritional and livelihood security with special reference to India: A review. Trop Anim Health Prod, 53(1): 176, doi: 10.1007/s11250-021-02621-6

Sankhyan V, Katoch S, Thakur YP, Dinesh K, Patial S et al., 2013. Analysis of characteristics and improvement strategies of rural poultry farming in north western Himalayan state of Himachal Pradesh, India. Livest Res Rural Dev, 25(12): 1-13

Scherr SJ and McNeely JA, 2008. Biodiversity conservation and agricultural sustainability: towards a new paradigm of 'ecoagriculture' landscapes. Philos Trans R Soc, 363(1491): 477494, doi: 10.1098/rstb.2007.2165

Shang Y, Kumar S, Oakley B and Kim WK, 2018.
Chicken gut microbiota: importance and detection technology. Front Vet Sci, 5: 254, doi: 10.3389/ fvets.2018.00254

Singh JL and Mohilal N, 2017. Gastrointestinal parasitic infection in diverse species of domestic birds of Manipur, India. J Parasitol Dis, 41(1): 142146, doi: 10.1007/s12639-016-0767-4

Thakur D, Sharma AK, Ravikumar RK and Katoch S, 2012. Status of backyard poultry farming in Himalayan regions of India. Indian J Poult Sci, 47(1): 102-105

Thornton PK, 2010. Livestock production: recent trends, future prospects. Philos Trans R Soc: B3652853B3652867, doi: 10.1098/rstb.2010.0134

Tufarelli V, Ragni M and Laudadio V, 2018. Feeding forage in poultry: A promising alternative for the future of production systems. Agriculture, 8(6): 81, doi: 10.3390/agriculture8060081

Vaarst M, Steenfeldt S and Horsted K, 2015. Sustainable development perspectives of poultry production. World's Poult Sci J, 71(4): 609-620, doi: 10.1017/S0043933915002433

Wakenell P, 2016. Management and medicine of backyard poultry. In Current Therapy in Avian Medicine and Surgery, pp 550-565, doi: 10.1016/ B978-1-4557-4671-2.00024-0

Wierup M, Wahlström H and Bengtsson B, 2021. Successful prevention of antimicrobial resistance in animals- A retrospective country case study of Sweden. Antibiotics, 10(2): 129, doi: 10.3390/ antibiotics 10020129

Zhao ZG, Li JH, Li X and Bao J, 2014. Effects of housing systems on behaviour, performance and welfare of fast-growing broilers. Asian-Australas J Anim Sci, 27(1): 140-146, doi: 10.5713/ajas.2013.13167

Received-25.09.2021, Accepted-13.11.2021, Published-01.12.2021

Section Editor: Dr. A. K. Patra, Associate Editor 